\title{
Revisão crítica da literatura brasileira sobre as coberturas jornalísticas esportivas do futebol feminino
}

http://dx.doi.org/10.11606/1807-5509202000030499

\author{
Bruno J osé GABRIEL* \\ Erica Fernanda de PAULA* \\ Bruno PEDROSO* \\ Miguel Archanjo de FREITAS J UNIOR* \\ Márcia Helena Baldani PINTO*
}

\section{Resumo}

Os objetivos deste artigo foram revisar e analisar criticamente a estruturação da literatura, publicada em periódicos científicos nacionais, que estabeleceu as coberturas jornalísticas impressas e digitais acerca do futebol feminino e das jogadoras como objeto de estudo. Para tanto, optou-se pela adoção dos direcionamentos da Revisão Crítica, complementados pelos instrumentos metodológicos da Análise de Conteúdo, pois estes guiam os pesquisadores no processo analítico dos diversos tipos de discursos, dentre estes, o acadêmico/científico. Após a análise crítica dos seis artigos encontrados, chegou-se a três considerações preponderantes, nomeadamente, insuficiência na apresentação das escolhas metodológicas, diálogo interdisciplinar insuficiente, sobretudo com as teorias do jornalismo, e necessidade de pesquisas complementares.

Palavras-chave: Jornalismo; Educação Física; Campo acadêmico/científico; Pesquisas científicas; Brasil.

\section{Introdução}

O esporte náo é criaçáo do presente. Em outra designação, o esporte é produto de conjunturas históricas precedentes, e ao longo destas, este acabou legitimado como um dos símbolos mais significantes em diversas culturas, atuando inclusive no processo de (re)estruturaçáo de espaços sociais específicos. Nesse sentido, Elias ${ }^{1}$ destacou que o esporte, ou os primórdios do que atualmente recebe esta designação, desempenhou um papel civilizador na cultura europeia, especificamente quando relativizou a violência das práticas físicas guerreiras, pois os diversos oponentes passaram a resolver as suas divergências mediante disposições regradas e respeitadas por ambas às partes.

Silva e Zamboni ${ }^{2}$ salientaram que, sintomático da significância cultural adquirida pelo esporte, são as integraçóes progressivas deste aos programas de Educação Física, as grades dos veículos comunicacionais, onde dispóe de significativo espaço em detrimento de outras temáticas, e as indústrias que o comercializam de distintas maneiras. Indústrias estas em constante ampliação.
Já Goellner ${ }^{3}$ argumentou que as modalidades esportivas presentes no território brasileiro integram o cotidiano dos residentes locais, envolvendoos como praticantes e/ou consumidores. Por conseguinte, estas acabam influenciando em distintas tomadas de posição, como sentimentos e representaçóes. Entretanto, vale ressaltar que, dentre essas modalidades esportivas, o futebol há muito tempo é a que detém a maior significância cultural ${ }^{4}$, aspecto que redimensiona as tomadas de posição mencionadas. Tal situação é facilmente observada durante a participação da seleção brasileira em uma Copa do Mundo, pois a rotina laboral e a arquitetura das cidades são significativamente alteradas. Os clubes, o comércio, as empresas, as escolas, as residências, as mídias, as Universidades e todos os setores da sociedade praticamente param para torcer pelo Brasil, integrando o verde e o amarelo em seus respectivos cotidianos.

Mesmo dispondo desse status, em diversos continentes, países e regiōes, o esporte e as suas interfaces tornaram-se objeto de estudos teóricos e 
aplicados das diversas áreas das ciências humanas e sociais subsequente a outras temáticas consideradas clássicas (a economia, a política, o trabalho $)^{5-7}$. Dentre outros aspectos, é comprobatória da situação mencionada anteriormente o crescimento considerável da Sociologia do esporte como área de especialização apenas na década de 1960, especialmente nos Estados Unidos, Canadá e Alemanha Ocidental 5 .

A partir de então, além de produçóes científicas foram criados eventos, periódicos, disciplinas específicas e associaçôes em âmbito internacional no interior da Antropologia, da História, da Sociologia, e de outras áreas, como a Educação Física. A América Latina e, conseguintemente, o Brasil, não ficaram alheios a estas criaçóes, embora as suas efetivaçóes sejam de um período subsequente, o final do século $\mathrm{XX}^{6-10}$. Assim, paulatinamente, os objetos científicos relacionados ao esporte em geral e às modalidades específicas, como o futebol, multiplicaram-se $e^{6,9,10}$. No Brasil, na década de 2000, o futebol feminino ${ }^{a}$, as jogadoras e as suas interrelaçóes com outras interfaces

\section{Método}

As classificaçóes deste estudo foram estruturadas por uma aplicabilidade, pois teve como objetivação estimuladora a aplicação, utilização e consequências práticas dos conhecimentos gerados, especificamente nas áreas interessadas em estudar de maneira mais qualificada as coberturas jornalísticas esportivas sobre o futebol feminino. Qualitativa quanto a abordagem do seu problema, uma vez que a compreensão das características apresentadas pelo material empírico foi essencial. Descritiva quanto ao seu objetivo, pois descreveu as particularidades do fenômeno pesquisado. Por fim, bibliográfica quanto aos procedimentos técnicos, uma vez que foi desenvolvida a partir de artigos científicos obtidos por meio de bases de dados específicas.

Para efetivar o delineamento e o objetivo geral optou-se pela adoção dos direcionamentos metodológicos da RC, um tipo específico de revisão de literatura, pois tem como finalidade o levantamento, a síntese e a análise crítica de bibliografias provenientes de qualquer área do conhecimento. Segundo Mancini e Sampaio ${ }^{12}$, as revisóes de literatura são caracterizadas pela sociais passaram a ser problematizadas mais intensamente, materializando novas pesquisas. Dentre estas, constatou-se as que estabeleceram as coberturas jornalísticas esportivas dos diversos dispositivos $^{\mathrm{b}}$ existentes (jornal, rádio, televisão e internet) sobre o futebol feminino e as jogadoras como objeto ${ }^{11}$.

Diante desta contextualização, emergiu a problemática, desdobrada no objetivo geral deste estudo, que revisou e analisou criticamente a estruturação da literaturac, publicada em periódicos científicos nacionais, que estabeleceu as coberturas jornalísticas esportivas impressas e digitais sobre o futebol feminino e as jogadoras como objeto. Para tanto, adotou-se os direcionamentos metodológicos da Revisão Crítica (RC), complementados pelos desígnios da Análise de Conteúdo (AC). A justificativa para esta realização foi alicerçada na inexistência de outras homólogas, materializando originalidade e relevância, e no conseguinte intento em contribuir com a qualificação das produçóes subsequentes que estabeleçam o mesmo objeto das pesquisas que foram aqui analisadas.

síntese e análise das informações disponibilizadas por todas as produçóes relevantes publicadas sobre um determinado objeto, de forma a resumir o corpo de conhecimento e levar a concluir em relação ao assunto de interesse.

Existem diversas tipos de revisão de literatura, cada qual seguindo ou não uma especificidade metodológica. Dentre estes está a RC, também conhecida como estudos passivos (sintetizam produçóes sobre um assunto), ou estudos opinativos (analisam a evidência existente sobre um assunto), por meio do qual os autores sintetizam e analisam as informaçôes disponibilizadas na literatura. Este estudo em específico não segue necessariamente uma metodologia pré-definida ${ }^{11}$.

Em complemento a esse direcionamento metodológico inicial, adotou-se os desígnios da $\mathrm{AC}$, pois estes direcionam os pesquisadores no processo analítico dos diversos tipos de discursos existentes. BARDIN ${ }^{13}$ a definiu como um conjunto de instrumentos metodológicos de análise das comunicaçóes, que visa obter, por intermédio de procedimentos sistemáticos e objetivos de 
descrição do conteúdo das mensagens, indicadores (quantitativos ou qualitativos) permissíveis de inferências sobre os conhecimentos relativos às condições de produção/recepção destas. $\mathrm{O}$ fator comum destes instrumentos múltiplos e multiplicados é uma hermenêutica controlada, baseada na dedução, a inferência.

Nesse sentido, aplicaram-se os instrumentos referentes às diferentes etapas que constituem a organização analítica da AC, estruturada em torno de três polos cronológicos: a pré-análise, a exploraçáo do material e os tratamentos dos resultados, as inferências e as interpretaçóes.

Durante a pré-análise, etapa organizacional do material empírico, foram realizadas as três missóes necessárias, que não são sucedidas, obrigatoriamente, segundo uma ordem cronológica. Quais sejam, a escolha dos documentos analisados, a indicaçáo do(s) objetivos e a eleição dos índices e dos indicadores que fundamentaram a análise final.

Todas as decisôes supracitadas resultaram da realização dos procedimentos das cinco subetapas da pré-análise. Iniciou-se pela primeira, a leitura flutuante, designação atribuída ao contato inicial e ao conseguinte conhecimento textual do(s) documento(s) a analisar, deixando-se invadir por impressóes e orientaçóes ${ }^{13}$.

Ao objetivar a RC da literatura que estabeleceu as coberturas jornalísticas esportivas impressas e digitais do futebol feminino como objeto, escolheu-se os artigos publicados em periódicos brasileiros como fontes analíticas. Esta ramificação comunicativa foi escolhida, pois, mesmo com a existência de outras, como monografias, dissertaçóes e teses provenientes dos cursos de pós-graduação stricto sensu e lato sensu, os pesquisadores, influenciados pelas lógicas de funcionamento da ciência nacional, utilizam os periódicos, sobretudo os indexados no Webqualis da Coordenação de Aperfeiçoamento de Pessoal de Nível Superior (CAPES), para a divulgação parcial e/ou total dos resultados publicados nos dispositivos mencionados.

Para a busca dos artigos publicados em periódicos brasileiros foram utilizadas as bases de dados Portal de Periódicos da CAPES, LILACS, SciELO e Scopus. A consulta foi realizada no mês de novembro de 2016, utilizando os seguintes descritores e palavras-chave, nas línguas portuguesa, inglesa e espanhola: futebol feminino, futebol feminino e jornalismo, futebol feminino e jornal, futebol feminino e revista, women's soccer, women's soccer and journalism, women's soccer and newspapper, women's soccer and magazine, fútbol femenino, fútbol femenino $y$ periodismo, fútbol femenino y periódico, fútbol femenino y revista. Optou-se por não delimitar temporalmente a busca. Assim, foi possível identificar a totalidade de bibliografia relacionada ao objeto em questáo.

O contato inicial e o conhecimento textual dos artigos ocorreram durante a coleta destes. Primeiramente, foram lidos os títulos e os resumos. Em caso de dúvida sobre inclusão ou exclusão, os textos foram lidos na íntegra, em um segundo momento. A partir destes procedimentos, delimitouse o corpus da pesquisa em seis artigos.

Os critérios de inclusão foram pesquisas que estabeleceram as coberturas jornalísticas esportivas impressas e digitais sobre o futebol feminino e/ ou as jogadoras como objeto, publicadas em periódicos nacionais, pois estes possuem lógicas de funcionamento que os distinguem dos estrangeiros. Foram excluídas as pesquisas que problematizaram aspectos anatômicos, biológicos, fisiológicos (lesóes, índice de massa corporal, a influência etária na performance esportiva), técnicos, táticos e disciplinares (a relação entre puniçóes e o resultado dos jogos), e, por fim, a relação entre a mulher e o esporte/futebol utilizando os produtos jornalísticos como fonte histórica. Ou seja, como material empírico único ou complementar para contextualizar tal fenômeno.

As tarefas da pré-análise foram encerradas por intermédio da referência dos índices (temáticas) e dos indicadores (presença ou ausência e frequência), da coleta dos artigos e da preparaçáo do material empírico, quarta e quinta etapas, respectivamente. $\mathrm{Na}$ sequência, efetivaram-se as tarefas da etapa denominada exploração do material. As tarefas desta consistiram, essencialmente, em operaçóes de codificação, desconto ou enumeração, relacionadas às escolhas anteriores.

Partiu-se do preceito de que, para explorar determinado documento, é preciso tratá-lo. Tratar os dados empíricos significa codificá-los. Segundo BARDIN ${ }^{13}$, codificação corresponde à transformação dos dados em bruto do texto, utilizando algumas regras. Transformação esta que por recorte, agregação e enumeração, permite que o pesquisador atinja a representação, a expressão e a significação dos conteúdos dos textos, esclarecendo as suas características que 
podem servir de índices.

A organização da codificação correspondeu a três definiçôes: 1 . O recorte: referiu-se às unidades de registro (UR) e às unidades de contexto (UC); 2. A enumeração: referiu-se às regras de contagem; 3: A classificação e a agregação: referiram-se às categorias analíticas.

As UR correspondem às unidades de significação a codificar, ao segmento do conteúdo a considerar como base, visando a categorização e a contagem frequencial. Estas podem ser de natureza e de dimensões muito variáveis, mas, normalmente, representam um recorte semântico, que pode ser estabelecido antes ou durante a leitura dos textos constituintes do corpus da pesquisa. Considerando tais aspectos, definiu-se que as UR desta pesquisa seriam as temáticas centrais que designaram estruturas científicas (a metodologia, teoria, resultados).

Já as UC correspondem aos segmentos dos textos cujas dimensóes (superiores às da UR) são adequadas para apreender a significação exata das UR. Por conseguinte, definiu-se que os parágrafos e/ou a junção de parágrafos que estruturaram os textos em sua totalidade seriam as UC das UR encontradas.

Definidas as UR e as UC, contou-se a totalidade

\section{Resultados e discussão}

Por intermédio da busca realizada emergiram 4.877 artigos, 3.907 no Portal de Periódicos da CAPES, 232 no LILACS, 102 na SciELO e 636 no Scopus, considerando as repetições próprias e compartilhadas. A partir dos critérios de inclusão/ exclusão, o corpus da pesquisa foi delimitado em seis artigos, apresentados a seguir no QUADRO 1:

Constatou-se que, embora a busca tenha sido realizada mediante bases de dados que contemplam artigos de maior e menor qualificação, predominaram publicaçóes em periódicos que se destacam entre seus pares, sobretudo para aqueles que perpassam a área na qual quatro ${ }^{e}$ deles estão estruturados, a Educação Física. Tal status é corroborado via indexação no SciELO (Motriz e Revista Brasileira de Educação Física e Esporte), disposição de fator de impacto Journal Citation Reports (JCR) (Movimento e Motriz) e/ou indicativo de qualidade disposto no Webqualis 2015.

Infere-se que a preponderância de publicaçôes em periódicos da Educaçâo Física pode estar relacionada à formação ou ao exercício profissional dos seus de artigos, classificando-os progressivamente em Art1, Art2 e assim sucessivamente até o Art6, correspondendo-os ao ano de publicaçáo, ao periódico, ao Qualis disponível no Webqualis 2015 referente a área de avaliação 21/Educação Física e a vinculação institucional dos autores além das UR emergidas (o que normalmente se conta). Estas últimas guiadas pelas regras de enumeraçáo denominadas de presença ou ausência, que expressa o apontamento e o não apontamento temático, e frequência, que expressa à quantidade de apontamentos. Diante destas definiçóes, optou-se por alocar as designaçóes das temáticas encontradas referentes à metodologia (categoria) em suas subcategorias (natureza, abordagem do problema, nível, procedimento técnico e instrumental analítico). Igualmente no que se refere à teoria (categoria), bourdeusiana, comunicacional, cultural, gênero e imaginário social (subcategorias), e resultados (categoria), baixa visibilidade, discursos mistos e discursos ausentes de preconceito (subcategorias). Por meio destas açóes foi possível efetivar os tratamentos dos resultados, as inferências e as interpretaçóes, últimas tarefas metodológicas da AC.

respectivos autores, pois todos estes têm alguma vinculação institucional com a referida área. Por mais que os profissionais tenham uma relativa autonomia em relação às lógicas de funcionamento da ciência, ou seja, ao periódico no qual vão submeter um artigo para avaliação, a CAPES considera a base formativa nas suas avaliaçôes. Sintomático, a título de exemplificação, é o fato de a Universidade Estadual de Ponta Grossa (UEPG) ainda não dispor de um Programa de PósGraduação stricto sensu em Educação Física. No caso dos discentes, as produçóes classificadas na respectiva área são normalmente as únicas válidas em processos seletivos para o ingresso na carreira docente nas Instituiçôes de Ensino Superior (IES).

Outros dados mereceram destaque, quais sejam a escassez de pesquisas, a contemporaneidade destas, o número de autores(as) e coautores(as) e as vinculaçôes institucionais destes(as). Os seis artigos coletados foram produzidos por treze pesquisadores(as), vinculados a treze IES, dez nacionais e três internacionais, e publicados entre anos de 2007 e 2016. 
QUADRO 1- Perfil dos participantes acolhidos na CT entre março e abril de 2017, n=17.

\begin{tabular}{|c|c|c|c|c|}
\hline Artigos & Ano de publicação & Autores & Periódico & $\begin{array}{c}\text { Qualis - Educação } \\
\text { Física* }\end{array}$ \\
\hline Art1 & 2007 & Martins e Moraes ${ }^{14}$ & Pensar a Prática & B2 \\
\hline Art2 & 2011 & $\begin{array}{l}\text { Ferretti, Zuzzi, Viana } \\
\text { e Vilha Junior }\end{array}$ & Motriz & B1 \\
\hline Art3 & 2013 & $\begin{array}{l}\text { Salvini e Marchi } \\
\text { Júnior }^{16}\end{array}$ & Espaço Plural & B3 \\
\hline Art 4 & 2013 & $\begin{array}{l}\text { Salvini e Marchi } \\
\text { Júnior }^{17}\end{array}$ & Movimento & $\mathrm{A} 2$ \\
\hline Art5 & 2013 & $\begin{array}{l}\text { Goellner, Silva e } \\
\text { Botelho-Gomes }^{18}\end{array}$ & Movimento & A2 \\
\hline Art6 & 2016 & $\begin{array}{l}\text { Gabriel e Freitas } \\
\text { Júnior } 19\end{array}$ & $\begin{array}{l}\text { Revista Brasileira de } \\
\text { Educação Física e } \\
\text { Esporte }\end{array}$ & B1 \\
\hline
\end{tabular}

Fonte: Os autores. Nota: A ordenação obedeceu ao seguinte critério: Antiguidade temporal, ordem alfabética dos periódicos e o número da publicação nestes.

* Qualis disponível no Webqualis 2015 referente a área 21/Educação Física.
A seguir, a TABELA 1 apresenta as vinculaçóes dos pesquisadores(as) às IES, baseadas nos cursos em nível de Pós-Graduação ou no vínculo institucional em vigência durante os anos nos quais os artigos foram publicados, relacionadas às alocaçóes geográficas destas.

Constatou-se que as vinculaçóes às IES, alternadas entre públicas e privadas, alocadas na região Sudeste, predominaram, totalizando sete $(43,75 \%)$ em relaçáo ao total (13). Duas à Universidade Estadual de Campinas (UNICAMP), uma à Universidade de Sáo Paulo (USP), uma ao Centro Universitário Adventista de São Paulo (UNASP), uma à Universidade Bandeirantes de São Paulo (UNIBAN), uma às Faculdades Integradas Einstein de Limeira (FIEL) e uma à Faculdade Morumbi Sul (FMS).

TABELA 1 - Vinculações dos pesquisadores(as) às IES relacionadas às alocações geográficas destas (2007-2016)

\begin{tabular}{lccc}
\hline IES/Regióes & Vinculaçóes & $\mathbf{F}_{\mathbf{i}} \mathbf{\%}^{*}$ & $\mathbf{F}_{\mathbf{a i}} \mathbf{\%}^{* *}$ \\
\hline Sul/Brasil & 5 & 31,25 & 31,25 \\
Sudeste/Brasil & 7 & 43,75 & 75,00 \\
Norte/Brasil & 1 & 6,25 & 81,25 \\
$\begin{array}{l}\text { Internacional/Por- } \\
\text { tugal }\end{array}$ & 2 & 12,50 & 93,75 \\
Internacional/EUA & 1 & 6,25 & 100,00 \\
Total & $16^{* * *}$ & 100,00 & 100,00 \\
\hline
\end{tabular}

Fonte: Os autores(as) *Frequência relativa em percentual.

**Frequência acumulada relativa.

***Três pesquisadores (as) tinham vinculações com duas IES. Por isso, o número total foi superior a 13. 
Cinco tinham vinculaçôes com IES públicas alocadas regionalmente no Sul. Duas à Universidade Federal do Paraná (UFPR), uma à Universidade Federal do Rio Grande do Sul (UFRGS) e duas à UEPG.

Uma vinculaçáo à IES pública alocada regionalmente no Norte, especificamente à Universidade Federal do Pará (UFPA). Além vinculaçóes citadas, três eram com IES internacionais. Uma a Faculdade de Desporto da Universidade do Porto (FADEUP), uma a Faculdade de Educaçáo Física e Desporto da Universidade Lusófona (FEFD) e uma a West Virginia University (WVU).

Dos seis, três artigos foram produzidos por pesquisadores(as) vinculados às mesmas IES. Um à UEPG, dois à UFPR, tratando-se, estes últimos, de autorias das mesmas pessoas. Entretanto, vale ressaltar, que uma delas atuou como docente visitante na WVU na ocasiāo da publicação.

Um artigo foi produzido mediante vinculaçóes a duas IES (UNICAMP e UNASP), ambas alocadas no estado de Sáo Paulo. Um dos artigos está vinculado a mais de duas IES (USP, UNICAMP, UNIBAN, FMS, FIEL e UFPA), alocadas em diferentes regiōes (Sudeste e Norte), e estados (São Paulo e Pará).

Um artigo foi produzido por pesquisadoras de diferentes países (Brasil e Portugal), vinculadas a três instituições (UFRGS, FADEUP e FEFD). Desta forma, pode-se afirmar que houve uma tentativa de diálogo institucional nacional e internacional, objetivando qualificar as produçóes e os conhecimentos das áreas nas quais transitam.

Acerca de uma das estruturas científicas dessas produçóes, especificamente a metodologia (categoria), verificou-se que em nenhum artigo houve menção referente à sua natureza (subcategoria). Ou seja, se eram de natureza básica/pura ou aplicada. Segundo $\mathrm{GIL}^{20}$, a pesquisa pura está direcionada para o progresso da ciência. Por meio dela os pesquisadores procuram desenvolver os conhecimentos sem preocupaçáo direta com as suas aplicaçóes e consequências práticas. A sua efetivação tende a ser bastante formalizada e objetiva à generalização, com vistas à construção de teorias e leis. Já a pesquisa aplicada, salientou o autor, tem como característica fundamental o interesse na aplicação, utilização e consequências práticas dos conhecimentos. Sua preocupação está menos voltada para o desenvolvimento de teorias de valor universal que para a aplicação imediata numa realidade circunstancial.

Em relaçáo à abordagem do problema (subcategoria), dos seis artigos analisados, três (Art2, Art5 e Art6) apontaram claramente no texto essa disposição. Todos se identificaram como qualitativos e quantitativos, ou seja, mistos. Apesar de os outros três não terem realizado apontamentos, estes utilizaram abordagens qualitativas.

Quanto aos níveis de pesquisa (subcategoria), dos seis artigos analisados, dois (Art1 e Art2) apontaram essa disposição, o primeiro descritivo e o segundo exploratório. Segundo Gil20, mesmo as pesquisas tendo um objetivo específico, é possível agrupá-las de maneira mais ampla em três níveis distintos, o exploratório, o descritivo e o explicativo.

$\mathrm{O}$ autor as distinguiu, argumentando que as pesquisas exploratórias têm como principal finalidade desenvolver, esclarecer e modificar conceitos e ideias, com vistas as formulaçóes de problemas mais precisos ou hipóteses pesquisáveis para estudos posteriores. Elas são desenvolvidas com o objetivo de proporcionar visão geral, de tipo aproximativo, sobre um determinado fato, especialmente quando a temática escolhida é pouco explorada e torna-se difícil formular hipóteses precisas e operacionalizáveis. As pesquisas descritivas têm como objetivo primordial a descrição das características de determinada população, fenômeno ou o estabelecimento de relações entre variáveis. São inúmeros os estudos que podem ser classificados sob este título e uma das suas características mais significativas está na utilização de técnicas padronizadas de coleta de dados. Já as pesquisas explicativas são aquelas que têm como preocupação central identificar os fatores que determinam ou contribuem para a ocorrência dos fenômenos. Estas são as que mais aprofundam o conhecimento da realidade, pois explica a razão, o porquê das coisas. Por isso mesmo é o tipo mais complexo e delicado, já que o risco de cometer erros aumenta consideravelmente.

Referente aos procedimentos técnicos (subcategoria), nenhum artigo apontou disposição correspondente. Os procedimentos técnicos são materializados em materiais empíricos. Segundo $\mathrm{GIL}^{20}$, existem diversos tipos, bibliográficos, documentais, experimentais, ex-post-factos, levantamentos (surveys), estudos de campo, estudos de caso, apropriados em função dos objetivos das pesquisas.

Os artigos analisados caracterizam-se como documentais, pois os materiais empíricos coletados pelos autores foram matérias jornalísticas esportivas. Martins e Moraes ${ }^{14}$ utilizaram a Folha de S. Paulo e O Estado de São Paulo, Ferretti, ZuzZi, Viana e VILHA JúNIOR ${ }^{15}$ e GABriel e Freitas JÚNIOR ${ }^{19}$, a Folha de S. Paulo, Salvini e Marchi Júnior ${ }^{16,17}$, a revista Placar, Goellner, Silva e Botelho-Gomes ${ }^{18}$, A Bola, Recorde, O Jogo On-line e o Norte Desportivo. Esse tipo de pesquisa apresenta singularidade quanto a natureza das fontes, que podem ser de primeira ou 
segunda mão. São fontes de primeira mão aquelas que não receberam tratamento analítico, como publicaçóes oficiais (leis, decretos e atas), produtos jornalísticos advindos dos dispositivos jornal, revista, televisão ou internet, cartas, fotografias e diários, impressos, sonoros ou visuais. Já as de segunda mão são aquelas que receberam alguma análise. Por exemplo, relatórios de pesquisa, relatórios empresariais e tabelas estatísticas ${ }^{20}$.

Quanto ao instrumental analítico (subcategoria), dos seis artigos analisados, quatro não evidenciaram no corpo do texto o referencial metodológico que embasou as análises empíricas. Os outros dois (Art5 e Art6) recorreram à $\mathrm{AC}$, referenciando a obra escrita por Laurence Bardin ${ }^{13}$. É contraditório afirmar que uma escolha é a mais adequada para determinado tipo de análise, pois existem diversas possibilidades. Entretanto, corrobora-se da acepção de Herscovitz ${ }^{21}$ de que a AC é um dos métodos mais eficientes devido à sua capacidade de fazer inferências. Amplamente empregada nas várias áreas das ciências humanas e sociais, a $\mathrm{AC}$ revelou-se bastante útil em pesquisas que estabelecem objetos jornalísticos.

Tal utilidade foi legitimada por SiLvA ${ }^{22}$, que, a partir do rastreamento do perfil da pesquisa em jornalismo no Brasil, problematizou as opçóes metodológicas dos pesquisadores(as) que analisaram matérias impressas. Segundo a autora, a Análise de Discurso $(\mathrm{AD})$ e a $\mathrm{AC}$ foram as escolhas mais frequentes, respectivamente. Além disso, também foi destacado que houve bastante negligência da seção Método, mesmo sendo esta uma estrutura científica teoricamente obrigatória.

A negligência dos artigos analisados nesta pesquisa representou 50\% do total. CÁCEREs, GÂNDARA e Puglisi ${ }^{23}$ argumentaram que, por mais óbvio que pareça, uma produção científica deve conter pontos-chave. A macroestrutura dos artigos originais normalmente utiliza o modelo IMRD (Introdução, Método, Resultados e Discussão), um formato não arbitrário que reflete diretamente o processo de criação e descoberta da ciência.

Os autores ainda ressaltaram que na seção Métodos são detalhados os procedimentos envolvidos na concretização da pesquisa, objetivando proporcionar a possibilidade de uma interpretação adequada dos resultados, e, em caso de interesse, as reproduçóes desta em outras realidades. Portanto, entende-se que a negligência dessa seção dificulta as ações mencionadas, influenciando de maneira negativa no avanço qualitativo das áreas acadêmicas, pois o exercício da ciência nunca parte do zero. Logo, as produçóes existentes são referências para as subsequentes.

Sobre a estrutura teoria (categoria), verificouse que, dos seis artigos analisados, um (Art1) não apontou a utilização de referencial. Os outros utilizaram uma ou mais teorias. Por conseguinte, optou-se por apresentar essas informações no QUADRO 2, a seguir, objetivando uma visualização mais didática.

QUADRO 2 - Teorias utilizadas nas seis pesquisas que compuseram o corpus da presente estudo.

\begin{tabular}{lcc}
\hline Artigos & Teoria & Referências \\
\hline Art2, Art3, Art4 e Art6 & Bourdieusiana & Bourdieu $^{24-30}$ \\
Art5 & Comunicacional & Wolf $^{31}$ \\
Art5 & Cultural & Não citou \\
Art2, Art5 e Art6 & Gênero & Scott ${ }^{32}$, Louro $^{33}$ \\
Art6 & Imaginário social & Baczko $^{34}$ \\
\hline
\end{tabular}

Apesar da diversidade teórica, constatou-se uma ausência em geral de referenciais teóricos articulados com bibliografias complementares do jornalismo, mesmo com a utilização das obras Sobre a Televisão e Teorias da Comunicação, escritas por Bourdieu ${ }^{28}$ e Wolf ${ }^{31}$, respectivamente. Considera-se que essas referências são de suma importância para a contextualização dos dispositivos delimitados, dos seus contextos, das suas características produtivas, aspectos influentes no produto jornalístico materializado nas páginas impressas e digitais dos jornais.

BorELli $^{35}$ esclareceu que, em relação às teorias 
jornalísticas e comunicacionais, existem basicamente dois direcionamentos. Aquele que compreende o jornalismo apenas como transmissor integra a teoria defensora de que este lugar, chamado de canal ou suporte, é puramente neutro, um simples veiculador de realidades. Para este, o jornalismo é apenas um lugar de passagem, que faz simplesmente a mediação entre os segmentos da sociedade (receptores). Neste contexto, basta apenas os jornalistas seguirem algumas normas (a objetividade, a neutralidade) materializadas nos manuais de redação para efetivar o trabalho produtivo.

Em oposição, salientou a autora, está o entendimento das outras correntes, desenvolvidas especialmente nas últimas décadas, que reconhece o trabalho jornalístico como uma atividade simbólica. A sua tarefa seria apontar a realidade segundo pontos de vista específicos. O jornalismo é entendido, então, como um dispositivo de produçáo de sentidos, onde se constrói e se faz uma oferta da realidade. Nesta perspectiva, cada jornal constrói acontecimentos singulares a partir de um fato único.

A adoçáo de um direcionamento teórico, como este último, por exemplo, articulado com bibliografias complementares que tratam de política editorial, processo produtivo, tipos jornalísticos (político, econômico, esportivo) e perfis profissionais qualificam as análises científicas. Portanto, defende-se a ideia de que os pesquisadore(as), sobretudo os exteriores ao jornalismo, considerando que a produção, o produto e o efeito ${ }^{22}$ integrados constituem o seu objeto de estudo, devem continuar adotando uma postura interdisciplinar. Entretanto, também precisam dialogar com as produçóes desta área.

Sobre a estrutura denominada resultados (categoria), dos seis artigos analisados, constatou-se a presença de três temáticas (subcategorias): 1) baixa visibilidade; 2) discursos mistos; 3) discursos ausentes de preconceito.

Referente a primeira subcategoria, a literatura científica publicada demonstrou que o futebol feminino teve baixa visibilidade nas coberturas jornalísticas esportivas de alguns veículos de comunicação nacionais e internacionais. Em alguns artigos, a outra interface generificada da modalidade, ou seja, a masculina, foi trazida a lume para reverberar esta demonstração.

Martins e Moraes ${ }^{14}$ analisaram as publicações sobre o futebol feminino e as jogadoras em dois jornais diários de circulação nacional, em meses antecedentes (maio e junho) e no mês de realização (agosto) dos Jogos Olímpicos de Atenas-2004. Em maio, O Estado de São Paulo não efetivou nenhuma publicação, e a Folha de S. Paulo duas, visibilidade bastante distinta da proporcionada ao futebol masculino. $\mathrm{O}$ mês de junho não apresentou uma variação significativa. A Folha de $S$. Paulo publicou duas matérias, e O Estado de São Paulo uma. Já em agosto foram trinta e quatro publicações na Folha de S. Paulo, e vinte e nove no jornal O Estado de São Paulo. Segundo os autores, esse acréscimo ocorreu em decorrência do desempenho satisfatório da seleção feminina, vice-campeã olímpica.

Ferretti, Zuzzi, Vianna e Vilha Junior ${ }^{15}$ analisaram as reportagens do caderno Pequim, confecção especial da Folha de $S$. Paulo para cobertura dos Jogos Olímpicos de 2008, entre os dias 05 e 25 de agosto, direcionadas aos futebóis nacionais. Eles demonstraram que a seleçáo feminina e as jogadoras foram abordadas, em geral, em menores proporçóes que as suas vertentes masculinas. Considerando o total de publicaçóes, quantidade que náo foi apresentada, as reportagens dos homens tiveram maior número de palavras $13.093(52,1 \%)$, a das mulheres 10.267 $(40,9 \%)$ e as mistas $1.764(7 \%)$. Em relação às fotografias complementares aos textos, as mulheres obtiveram superioridade numérica, com $7.918 \mathrm{~cm}^{2}$ (47,9\%), contra 7.775,5 $\mathrm{cm}^{2}(46,9 \%)$ dos homens e $859,2 \mathrm{~cm}^{2}(5,2 \%)$ de ambos os gêneros. A título de complementação contextual, os autores apontaram que no mesmo período o caderno esportivo desse jornal não publicou matérias acerca do futebol feminino clubístico. Já o futebol masculino foi preponderante, sobretudo as coberturas das séries $\mathrm{A}$ e B do Campeonato Brasileiro.

GABRIEL e FrEITAS JÚNIOR ${ }^{19}$ analisaram a cobertura esportiva da Folha de $S$. Paulo referente à seleção brasileira e as jogadoras entre 01 de janeiro e 31 de dezembro de 2011, ano de realização da Germany Women's World Cup. Por intermédio do buscador do jornal e das palavras-chave seleção feminina e Brasil, foram encontradas trinta e sete matérias, número considerado muito baixo, pois representa 3,08 publicaçóes mensais. Outro aspecto constatado foi a maior visibilidade coletiva e individual durante a ocorrência do campeonato mundial ( 26 de junho a 17 de julho), treze matérias. Outras duas competiçóes foram disputadas em 2011, os Jogos Pan-Americanos, entre 14 e 30 de outubro, no México, e o Torneio Internacional Cidade de Sáo Paulo, no Brasil, entre 08 e 18 de dezembro. Estas foram desdobradas em nove e três publicaçóes, respectivamente. Ou seja, pode-se afirmar que a maior visibilidade do futebol feminino esteve (e está) condicionada aos momentos de ocorrência das competiçôes, representando $67,57 \%$ do total.

Goellner, Silva e Botelho-Gomes ${ }^{18}$ analisaram a 
cobertura esportiva de alguns jornais digitais de Portugal acerca do futebol praticado por mulheres, antes, durante e depois da ocorrência da Algarve Women's Football Cup2012. Nesse período, mais especificamente entre 27 de fevereiro e 08 de março de 2012, o jornal A Bola online (fonte primária) publicou dez edições, desdobradas em 949 reportagens, dentre as quais somente cinco $(0,52 \%)$ eram consoantes com os objetivos da pesquisa. O jornal Recorde publicou dezessete reportagens, $\mathrm{O}$ Jogo $\mathrm{On}$-Line quatro e $\mathrm{O}$ Norte Desportivo uma (fontes complementares). Segundo as autoras, esses números expressam a baixa visibilidade, ou sub-representação do futebol praticado pelas mulheres no jornalismo esportivo de Portugal, sobretudo se comparado com o praticado pelos homens, preponderante nesses veículos comunicacionais.

Além dos resultados numéricos, esses e os outros artigos também analisaram os aspectos qualitativos da cobertura esportiva sobre o futebol feminino e as jogadoras, ou seja, os discursos materializados em publicações e as suas características. Desta forma, foram observadas duas caracterizaçóes antagônicas. A primeira refere-se a discursos mistos (subcategoria), que representam a oscilação entre o apontamento de disposiçóes preconceituosas e ausentes de preconceito nas matérias dos jornais analisados.

SALVINI e MARCHI JÚNIOR ${ }^{17}$ analisaram a cobertura da revista Placar acerca do futebol feminino entre 1980 e 1990. Os autores constataram que o veículo tinha uma seção dedicada à opinião dos leitores, que proporcionava visibilidade às falas de mulheres simpatizantes ao futebol. Estas falaram de reivindicaçóes, possibilidades futebolísticas, direito em praticá-lo e que esta prática esportiva não era determinante da homossexualidade e da masculinização da mulher. Tal tomada de posição não foi considerada totalmente ausente de preconceitos, pois a revista demorou a proporcionar visibilidade aos desdobramentos da estruturação do futebol feminino brasileiro. Por exemplo, a existência do Esporte Clube Radar, equipe de maior status a época. Quando o fez, vinculou a imagem das atletas à feminilidade normativa.

Nesse contexto, a revista Placar também proporcionou visibilidade às Globetes, cujo objetivo precípuo não era o desempenho, mas sim a exposição da beleza da mulher futebolista. Até as matérias que tratavam de equipes competitivas enfocavam ações de feminilização das atletas antes dos jogos. Mas esta tomada de posição não foi considerada totalmente preconceituosa, pois as imagens que acompanharam algumas matérias refletiam futebolistas realizando gestos técnicos da modalidade. Martins e MoraEs ${ }^{14}$ constataram que, no período antecedente ao início dos Jogos Olímpicos de Atenas-2004, a Folha de S. Paulo publicou uma coluna considerada preconceituosa, denominada "O tedioso futebol feminino", argumentando que a participação da seleção feminina em um megaevento não desperta as mesmas atitudes sociais, como ocorre quando se trata da interface masculina. Mas, tanto esse jornal quanto O Estado de Sáo Paulo efetivaram registros sobre a futura participação olímpica. Esta tomada de posição não foi considerada totalmente ausente de preconceito, pois também representou uma negligência ao futebol feminino e às futebolistas clubísticas.

Segundo os autores, durante o período de ocorrência da Olimpíada, de maneira geral, a cobertura dos dois jornais pareceu estar mais atenta aos corpos das mulheres, com adjetivaçóes negativas (sexo frágil) e comparaçóes entre homens e mulheres. Entretanto, conforme a seleção foi vencendo, algumas publicaçôes trataram dos aspectos técnicos, táticos e disciplinares articuladas às adjetivaçóes positivas (pequenas grandes mulheres) além do status e das possibilidades futuras do futebol feminino e das futebolistas brasileiras.

Ferretti, Zuzzi, Viana e Vilha Junior ${ }^{15}$ constataram, desconfiadamente, que durante a ocorrência dos Jogos Olímpicos-2008 o caderno Pequim da Folha de S. Paulo publicou uma reportagem em específico abordando o entorno da partida Brasil versus Alemanha e a abertura do torneio futebolístico, prioritariamente, secundarizando os aspectos técnicos, táticos e disciplinares. Segundo os autores, outras reportagens também foram preconceituosas, desvalorizando o esforço das jogadoras, pois as imagens que as acompanham enfocam os jogadores da equipe masculina, que assistiam ao jogo em questão, Brasil versus Coréia do Norte, e a emotividade feminina, consequência da derrota na disputa da medalha de ouro diante dos Estados Unidos.

Em se tratando das imagens, os corpos das futebolistas foram erotizados, mas em menor proporção do que os das atletas de outras modalidades. Em sentido oposto, alguns elementos biográficos da jogadora Marta, aspectos técnicos, táticos e disciplinares da seleção brasileira, o elogio aos resultados femininos diante da falta de apoio do governo e das instituiçóes esportivas e a valorização das mulheres em relação aos homens também obtiveram visibilidade nas reportagens analisadas.

Goellner, Silva e Botelho-Gomes ${ }^{18}$ constataram que a cobertura qualitativa dos jornais analisados acerca do futebol praticado por mulheres em Portugal também apontou para uma sub-representação. Durante o período de ocorrência da Algarve Women's World Cup- 
2012, as matérias publicadas abordaram os resultados das partidas, os gols marcados, o nome da atleta que os fizeram e o tempo de jogo em que aconteceram. Tais tomadas de posição não foram consideradas ausentes de preconceito, pois além dos textos serem bastante curtos, nenhum destes conferiu voz às atletas e apenas uma entre as imagens que acompanharam as matérias exibiu uma jogadora executando gestualidades técnicas da modalidade. Por fim, em uma seção específica, denominada a Bola de Estrelas, os corpos de futebolistas e personalidades não esportistas foram abordados, enfatizando uma dada representaçáo de feminilidade, na qual os atributos estéticos suprimem os técnicos, subvalorizando as realizaçóes esportivas.

De maneira oposta, na cobertura do Recorde foram conferidas vozes às mulheres, como Carla Couto (atleta da seleçáo portuguesa), Mônica Jorge (ex-técnica da seleção portuguesa e a época dirigente da Federação Portuguesa de Futebol), Susana Cova (técnica adjunta de Portugal), Pia Sundhage (a época técnica da seleção americana) e Joseph Blatter (a época presidente da Fédération Internationale de Football Association - FIFA). E as imagens que estão articuladas aos seus textos expressam gestos técnicos da modalidade. Na matéria publicada no jornal O Norte Desportivo, apesar de um texto bastante curto, as mulheres também tiveram as suas vozes visibilizadas, mais especificamente Aya Miyama (seleção japonesa) e Nadine Angerer (seleção alemã).

Além dessa subcategoria, constatou-se outra, conforme mencionado anteriormente, caracterizada por discursos ausentes de preconceito. SALVINI e MARCHI JúNIOR ${ }^{16}$ analisaram a cobertura da revista Placar sobre Marta entre 2000 e 2010. De maneira geral, esse veículo abordou diretamente ou indiretamente alguns aspectos da sua trajetória de vida, como a dificuldade financeira no início da carreira, as vinculações clubísticas, a participação em documentário biográfico, a habilidade esportiva, as premiaçóes vinculadas à FIFA, as competiçôes, os patrocínios, as participaçôes na seleção brasileira, a relaçáo entre status individual e coletivo no Brasil, idolatria compartilhada, comparaçóes com homens futebolistas e a representação perante a seleção e o futebol feminino nacional.

Gabriel e Freitas Júnior ${ }^{19}$ constataram que, de uma maneira geral, a cobertura do caderno esportivo da Folha de S.Paulo, em 2011, acerca do coletivo da seleçáo brasileira de futebol feminino, abordou a preparação, os treinos, os resultados, as competiçóes, a técnica, a tática, as vitórias, a derrota, a significância social, a estrutura e a comparação com a equipe masculina. No que se refere à individualidade, o jornal tratou dos desempenhos positivos e negativos, das premiaçóes, dos status futebolísticos e da superioridade feminina em relação a alguns homens na modalidade.

Por meio da literatura analisada, percebeu-se que algumas coberturas jornalísticas esportivas nacionais e internacionais oscilaram entre a construção de discursos mistos. Ou seja, que em momentos específicos apresentaram disposiçóes preconceituosas, mas em outros não, ou lineares na ausência de preconceito. Levando em consideração as teorias jornalísticas e comunicacionais que entendem que cada dispositivo constrói uma cobertura singular, as especificidades intervenientes nos processos produtivos podem explicar as divergências, as convergências e as contradiçôes nos resultados obtidos pelos autores. Entretanto, o fato de a Folha de S. Paulo ter sido apontada por Martins e Moraes ${ }^{14}$ e Ferretti, Zuzzi, Viana e VILHA JUNIOR ${ }^{15}$ como produtora de uma cobertura esportiva mista chamou a atenção, pois outas pesquisas constataram o contrário.

Além do estudo mencionado de Gabriel e Freitas JÚNIOR $^{19}$, em outras pesquisas GABRIEL, FREITAS JÚNIOR e SCHIMANSKI ${ }^{37}$ constataram que entre 1991 e 2011 os aspectos técnicos, táticos e os resultados das partidas preponderaram na cobertura esportiva da Folha de $S$. Paulo. Segundo os autores, as matérias externaram em diversos momentos positividade à equipe nacional e às jogadoras, sobretudo à Marta. Ambas foram apontadas como as verdadeiras representantes do futebol arte, estilo que há muito tempo é utilizado para distinguir a performance brasileira da europeia, mas que não vinha sendo materializado ao longo das décadas pelos futebolistas. Estes estavam priorizando o uso da força, do condicionamento e da organização táticaga. Uma hipótese bastante plausível para esta contradição pode estar associada às subjetividades dos pesquisadores inerentes em todas as análises qualitativas ${ }^{20}$.

Os estudos convergiram no tocante à baixa visibilidade proporcionada pelos diferentes jornais analisados ao futebol feminino e as jogadoras. De maneira geral, os autores contextualizaram essa condiçâao e a sua permanência ao longo do tempo. Mas, eles não problematizaram ambas as condições. Por conseguinte, emergem algumas questóes: $\mathrm{O}$ que significa uma baixa visibilidade? Por que o futebol feminino e as jogadoras continuam dispondo dessa condiçâo em alguns jornais? Esta é decorrente da falta de interesse do público ou este não se interessa em função da cobertura pífia? A baixa visibilidade pode ser considerada como produto de tomadas de posiçáo preconceituosas pelos jornais? 
Entende-se que para responder a estas indagações, objetivação não pretendida nesta pesquisa, e, por conseguinte, avançar em qualidade, as subsequentes deveriam problematizar as lógicas do jornalismo e a relativa autonomia disposta pelos jornais brasileiros. Ao fazê-las, também é necessária uma postura interdisciplinar, ou seja, dialogar com outras áreas do conhecimento.

Vale ressaltar que os veículos de comunicação são permeados por lógicas sociais específicas e gerais. Uma destas últimas caracterizam a economia da sociedade brasileira como capitalista, impondo a objetivação pela maior lucratividade possível. Logo, as temáticas significantes para a sociedade/ leitor/receptor, que proporcionam vendagem ou acesso, dependendo da plataforma do dispositivo, tenderiam a prioridade de publicação ${ }^{38}$.

BERGER $^{39,40}$, sob um viés jornalístico, oferta um panorama interessante desse assunto. Segundo a autora, é uma sugestấo interessante pensar, como critério de passagem do acontecimento à notícia, o espaço que este poderá ocupar numa página de jornal. Mais interessante ainda é o outro sentido de caber, pois o acontecimento deve ser compatível com a estrutura editorial, ou seja, deve caber também na ideologia do jornal.

A aprovaçấo do anunciante e a apreciaçáo do leitor foram acrescidas às lógicas que ajudam a definir a noticiabilidade e à natureza da imprensa. Seguindo essa lógica de funcionamento específica, a questão para os editores jornalísticos seria a seguinte: o que há de novo no mundo hoje que caiba no jornal (nos dois sentidos), conquiste leitores e não se confrontem com os seus sustentadores econômicos?

Ela ainda salientou que, neste contexto, encontram- se os indicadores para a compreensão do jornalismo: os vínculos com o mercado (patrocinadores e consumidores) e a equaçáo do vivido num espaço editável. Alguns jornais tendem a adotar uma postura mais independente, demonstrando as suas relativas autonomias às pressões externas por meio lógicas específicas, menos submetidas às intençóes de lucratividade. Entretanto, as tendências predominantes acentuadas ao longo do desenvolvimento do capitalismo é a sua função mercadológica e o conseguinte estreitamento dos seus vínculos com o poder econômico e político.

Por fim, qual seria a postura mais correta, um jornal capitalista ortodoxo ou relativizado? Difícil responder. Não obstante, essa indagação também necessita de problematizaçáo subsequente, transcendendo os limites objetivados nesta pesquisa.

Após o tratamento dos resultados, as inferências e as interpretaçôes, considera-se que, embora significante, considerando os dispositivos nos quais os artigos foram publicados, a literatura que estabeleceu as coberturas jornalísticas impressas e digitais sobre o futebol feminino e as jogadoras como objeto, deixou algumas lacunas. Lacunas estas que precisam ser transpostas em pesquisas homólogas subsequentes.

A primeira lacuna foi o delineamento metodológico insuficiente, condiçáo que dificulta a reprodução deste tipo de estudo em outras realidades. A segunda foi o diálogo interdisciplinar insuficiente, que empobrece as análises referentes ao objeto científico do jornalismo. Já a terceira desdobra-se na necessidade de investigações complementares futuras, como a significação de uma baixa visibilidade jornalística, a produção noticiosa em sociedades capitalistas e a análise discursiva padronizada, entre outras.

\section{Notas}

a. Outras designações passaram a ser utilizadas recentemente em contraposição ao termo futebol feminino, embora este ainda predomine em pesquisas. Goellner, Silva e Botelho-Gomes ${ }^{13}$ utilizaram a designação "futebol praticado por mulheres". Segundo as autoras, sob a ótica dos estudos de gênero, ocorre uma sugestão a alteração conceitual e política em relação a utilização predominante mencionada, pois compreende-se que o masculino e o feminino são atributos culturais e não necessariamente relacionados ao sexo biológico. Almeida ${ }^{41}$ coaduna com Goellner, Silva e Botelho Gomes $^{17}$. Para esta autora, ao futebol não se pode atribuir características de gênero, pois estas restringem a modalidade e as suas jogadoras. Por conseguinte, ela entende que a expressão "futebol de mulheres" é mais apropriada.

b. Segundo Mouillaud ${ }^{42}$, os dispositivos são os lugares materiais ou imateriais nos quais se inscrevem os textos (despachos de agências, jornal, livro, rádio, televisão). Os textos são quaisquer formas (de linguagem, icônico, sonora, gestual etc.) de inscrição. O dispositivo tem uma forma que é a sua especificidade. Não obstante, ele não é um "suporte", mas uma "matriz" que impóe suas formas aos textos. 
c. Nesta pesquisa utiliza-se literatura como um termo que abrange o material bibliográfico que aborda determinados objetos científicos. Para maiores aprofundamentos, vale consultar os argumentos de MAtTos, Rossetto Júnior e BLECHER ${ }^{43}$.

d. Para maiores aprofundamentos, consultar a obra de $\mathrm{GIL}^{20}$.

e. A única exceção é a Revista Espaço Plural, que está vinculada ao Centro de Ciências Humanas, Educação e Letras da Universidade Estadual do Oeste do Paraná (UNIOESTE), Campus de Marechal Cândido Rondon. No entanto, o referido Centro tem os seguintes cursos em sua alocação: Bacharelado e Licenciatura em Educação Física, Licenciatura Plena em Geografia, Licenciatura em História, Licenciatura em Letras-Português-Alemão, Licenciatura em Letras-Português-Espanhol e Licenciatura em Letras-Português-Inglês. Logo, tal periódico está interrelacionado a diversos subcampos acadêmicos/científicos.

f. Interdisciplinaridade é entendida a partir da proposição de Munhoz e Oliveira Junior ${ }^{44}$, qual seja a de que ela se refere à materialização de um diálogo entre os conhecimentos de distintos subcampos acadêmicos/científicos durante uma contextualização científica.

g. VoGeL ${ }^{45}$ fez uma distinção bastante aceita no campo científico entre futebol arte e futebol força.

\section{Abstract \\ Critical review of the Brazilian literature about sports news coverings of women's soccer}

The objectives of this study were to critically review and analyse the literature, published in national scientific journals, which established the printed and digital sports news coverings about women's soccer and its players as object of study. Therefore, it was opted for the adoption of directions of critical review, complemented by the methodological instruments of the so called Content Analysis, because they guide the researches on analysis of several discourses, among them, the academic/scientific. After the critical analysis of the six studies found, we came to three considerations, namely, insufficiency in the presentation of methodological choices, insufficient interdisciplinary dialogue, especially with theories of journalism, and need for complementary researches.

KeYwords: Journalism; Physical Education; Academic/scientific field; Scientific researches; Brazil.

\section{Referências}

1. Elias N. A génese do desporto: um problema sociológico. In: Elias N, Dunning E. A busca da excitação. Lisboa: Difusão editorial; 1992. p. 187-221.

2. Calil e Silva A; Zamboni MJ. Educação Física, esporte e cultura no Ensino Superior: íntimas relaçôes com o Brasil e a atualidade. Motriz. 2010:16;1051-1051.

3. Goellner SV. Mulher e esporte no Brasil: fragmentos de uma história generificada. In: Simões AC, Knijnik JD, organizadores. O mundo psicossocial da mulher no esporte: comportamento, gênero, desempenho. São Paulo: Editora Aleph; 2004. p. 361-73.

4. Daolio J. O drama do futebol brasileiro: uma análise socioantropológica. In: Daoilio J, organizador. Cultura: educação física e futebol. 3a ed. Campinas: Editora da UNICAMP; 2006. p. 107-114.

5. Dunning E. Prefácio. In: Elias N, Dunning E. A busca da excitação. Lisboa: Difusão editorial; 1992. p. 11-37.

6. Alabarces P. A pesquisa argentina: um mapa, uma agenda. In: Ribeiro L, organizador. Futebol e globalização. Jundiaí: Fontoura; 2007. p. 163-186.

7. Subúrbio: celeiro de craques. In: DaMatta R, organizador. Universo do futebol: esporte e sociedade brasileira. Rio de Janeiro: Pinakotheke; 1982. p. 59-74.

8. Assumpção LOT; Sampaio TMV; Caetano JNN; Caetano Júnior MA, Silva JVP. Temas e questóes fundamentais na sociologia do esporte. R Bras Ci Mov. 2010:18;92-99.

9. Helal R. Prefácio - O esporte na imprensa ou a imprensa no esporte? In. O esporte na imprensa e a imprensa esportiva 
no Brasil. Rio de Janeiro: 7Letras; 2012. p. 9-14.

10. Damo AS. Monopólio estético e diversidade configuracional no futebol brasileiro. Movimento. 2003:9;129-156.

11. Dinâmicas, estruturas e obstáculos no futebol amador feminino no Rio de Janeiro. Esporte Soc. 2016:11;1-16.

12. Mancini MC; Sampaio RF. Quando o objeto de estudo é a literatura: estudos de revisão. Rev Bras Fisioter. 2006:10;361472.

13. Bardin L. Análise de conteúdo. São Paulo: Ediçóes 70; 2011.

14. Martins LT, Moraes L. O Futebol Feminino e sua inserção na mídia: a diferença que faz uma medalha de prata. Pensar Prática. 2007:10;69-81.

15. Ferretti MAC, Zuzzi RP, Viana AES, Vilha Junior, FM. O Futebol feminino nos Jogos Olímpicos de Pequim. Motriz. 2011;17:117-27.

16. Salvini L, Marchi Junior W. O futebol de Marta na revista placar: recortes de uma história. Espaço Plural. 2013:16;298313.

17. Salvini L, Marchi Junior W. Uma história do futebol feminino nas páginas da Revista Placar entre o ano de 1980-1990. Movimento. 2013:19;95-115.

18. Goellner SV, Silva P, Botelho-Gomes P. A sub-representação do futebol praticado por mulheres no jornalismo esportivo de Portugal: um estudo sobre a Algarve Women's footbaal cup. Movimento. 2013:19; 171-89.

19. Gabriel BJ; Freitas Júnior MA. O discurso acerca da seleção brasileira presente na Folha de S. Paulo durante o ano de realização da "Germany World Cup”. Rev Bras Educ Fís Esporte. 2016:30;371-83.

20. Gil AC. Métodos e técnicas de pesquisa social. 6a ed. São Paulo: Atlas; 2008.

21. Herscovitz HG. Análise de conteúdo em jornalismo. In: Lago C, Benetti M, organizadores. Metodologia de Pesquisa em Jornalismo. Petrópolis: Vozes; 2007. p. 123-42.

22. Silva G. Problemática metodológica em jornalismo impresso. Rumores. 2008:2;1-9.

23. Cáceres AM, Gandara JP, Puglisi ML. Redação científica e a qualidade dos artigos: em busca de maior impacto. J Soc Fonoaudiol. 2011:4;401-406.

24. Bourdieu P. Questóes de sociologia. Rio de Janeiro: Marco Zero; 1983.

25. Bourdieu P. A dominação masculina. Educação e realidade. 1995:20;133-84.

26. Bourdieu P. Razões práticas: sobre a teoria da ação. Campinas: Papirus; 1996.

27. Bourdieu P. A economia das trocas linguísticas: o que falar quer dizer. São Paulo: EDUSP; 1996.

28. Bourdieu P. Sobre a televisão. Rio de Janeiro: Jorge Zahar; 1997.

29. Bourdieu P. A distinção: crítica social do julgamento. Porto Alegre: Zouk; 2008.

30. Bourdieu P. O poder simbólico. Rio de Janeiro: Bertrand Brasil; 2010.

31. Wolf M. Teorias da comunicação. Lisboa: Editorial Presença; 2001.

32. Scott JW. Gênero: uma categoria útil de análise histórica. Educ Realidade. 1995:10;71-99.

33. Louro GL. Nas redes dos conceitos de gênero. In: Lopes MG, Meyer D, Waldow V, organizadores. Gênero e Saúde. Porto Alegre: Artes Médicas; 1996. p. 12-19.

34. Baczko B. A Imaginação social. In: Leach E et al., organizadores. Anthropos-Homem. Lisboa: Imprensa Nacional/ Casa da Moeda; 1985. p. 296-332.

35. Borelli V. Jornalismo como atividade produtora de sentidos. Disponível em: <http://www.bocc.ubi.pt/>. Acesso em: 30 nov. 2016.

36. Gabriel BJ. A cobertura acerca da Seleção Brasileira de futebol feminino realizada pelo caderno de esporte da Folha de S. Paulo (1991-2011) [dissertação]. Ponta Grossa (PR): Universidade Estadual de Ponta Grossa, Programa de Pós-Graduação em Ciências Sociais Aplicadas; 2015.

37. Gabriel BJ, Freitas Júnior MA, Schimanski E. A cobertura acerca da seleção brasileira de futebol feminino produzida pelo caderno de esporte do jornal Folha de S. Paulo (1991-2011). In: Antunes AC, Raiher AP, organizadores. Caderno de Pesquisa Social 3: Cidadania e democracia. Ponta Grossa: UEPG; 2016. p. 65-74.

38. Borelli V. Cobertura midiática de acontecimentos esportivos: uma breve revisão de estudos. In: Anais do 24. Congresso Brasileiro da Comunicação; 2001 set 1-15; Campo Grande, Brasil. Campo Grande: Sociedade Brasileira de Estudos Interdisciplinares da Comunicaçáo; 2001. p. 1-15.

39. Berger C. Do Jornalismo: toda notícia que couber, o leitor apreciar e o anunciante aprovar, a gente publica. In: Mouillaud M, Porto SD, organizadores. O jornal: da forma ao sentido. Brasília: Paralelo 15; 1997. p. 273-284.

40. Berger C. Campos em confronto: a terra e o texto. 2a ed. Porto Alegre: Editora UFRGS; 2003.

41. Almeida SA. "Boas de bola": um estudo sobre o ser jogadora de futebol no Esporte Clube Radar durante a década de 
Gabriel BJ , et al.

1980 [dissertação]. Florianópolis (SC): Universidade Federal de Santa Catarina; 2013.

42. Mouillaud M. Da forma ao sentido. In: Mouillaud M, Porto SD, organizadores. O jornal: da forma ao sentido. Brasília: Paralelo 15; 1997. P. 29-35.

43. Mattos MG; Rossetto Júnior AJ; Blecher S. Metodologia da pesquisa em Educação Física: construindo sua monografia, artigos e projetos. São Paulo: Phorte; 2008.

44. Munhoz DEN, Oliveira Junior CR. Interdisciplinaridade e pesquisa. In: Bourguignon JA, organizadora. Pesquisa social: reflexóes teóricas e metodológicas. Ponta Grossa: Todapalavra; 2009. p. 11-33.

45. Vogel, A. O momento feliz. Reflexóes sobre o futebol e o ethos nacional. In: DaMatta R, organizador. Universo do futebol: esporte e sociedade brasileira. Rio de Janeiro: Pinakotheke; 1982. p. 75-115.

ENDEREÇO

Bruno J osé Gabriel

Av. General Carlos Cavalcanti, 4748 - Uvaranas

84030-900 - Ponta Grossa - PR - Brasil

E-mail: brunogabriel_uepg@hotmail.com
Submetido: 02/08/2017

Revisado: 12/ 12/ 2017

Aceito: 29/03/2018 